\title{
Metástasis orbitaria de hepatocarcinoma
}

\section{Orbital metastasis of hepatic carcinoma}

\author{
Ángela Lamarca, Beatriz Jiménez • Madrid (España)
}
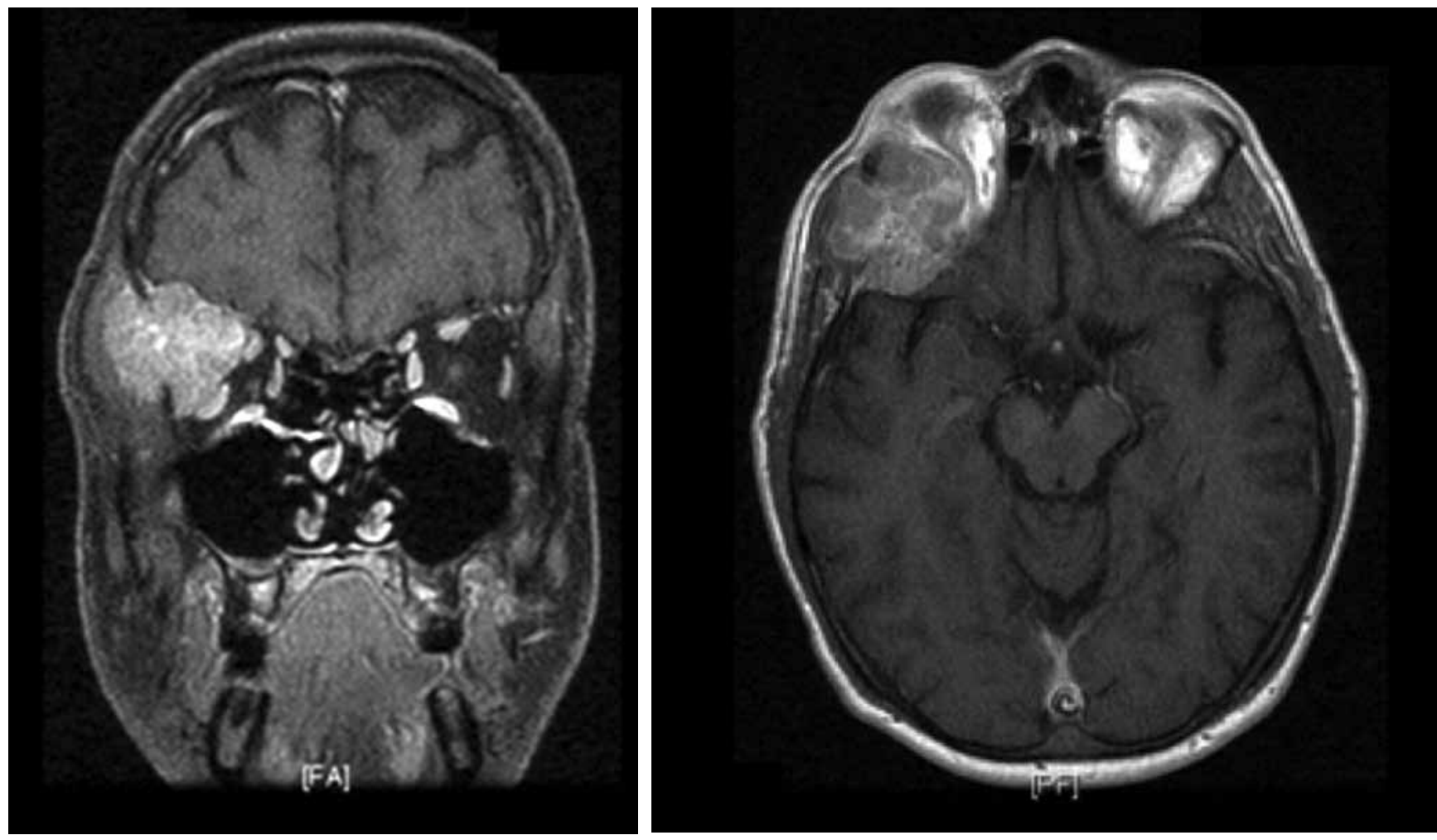

Palabras clave: hepatocarcinoma, metástasis óseas, cráneo

Keywords: Hepatocellular carcinoma, bone metastases, skull

Varón de 43 años sin antedecentes personales de interés. Es atendido en el servicio de urgencias por diplopía de un mes de evolución. En la exploración física se objetiva proptosis importante del ojo derecho. En las pruebas de imagen [TC y RNM (Figuras 1 y 2)] se objetiva una masa sólida en la pared ósea interna de la órbita derecha de $3.8 \times 4.2 \times 3.3 \mathrm{~cm}$ con importante crecimiento intraorbitario e infiltración de glándula lacrimal y músculos orbitarios. Se procedió a biopsia diagnóstica de la lesión, con diagnóstico histológico de hepatocarcinoma. El estudio de extensión con PET-TC y gammagrafía ósea fue negativo, sin lesiones focales hepáticas significativas ( $\sin$ poder descartar infiltración difusa). En la analítica la alfafetoproteína fue de $8,82 \mathrm{ng} / \mathrm{ml}$ y el estudio serológico de hepatitis virales negativo. El paciente niega historia de enolismo crónico así como posibles antecedentes de hepatopatía. Tras el diagnóstico, la enfermedad tuvo un curso rápidamente progresivo con aparición de múltiples metástasis óseas y deterioro rápido del estado general a pesar del tratamiento sistémico con sorafenib. Falleció a los ocho meses del diagnóstico.

Dras. Ángela Lamarca Lete y Beatriz Jiménez Muñarriz: Servicio de Oncología Médica. Hospital Universitario La Paz, Madrid (España).

Correspondencia: Dra. Ángela Lamarca, Madrid (España).

E-mail: angelalamarca@ hotmail.com. Recibido: 20/II/2012 Aceptado: 07/III/2012 